\title{
Quality of life in patients with coronary heart disease after myocardial infarction and with ischemic heart failure
}

Joanna M. Moryśs ${ }^{1,2}$, Jerzy Bellwon², Stefan Höfer ${ }^{3}$, Andrzej Rynkiewicz ${ }^{4}$, Marcin Gruchała²

${ }^{1}$ Department of Clinical Psychology, Medical University of Gdansk, Gdansk, Poland ${ }^{2} 1^{\text {st }}$ Cardiology Clinic, Medical University of Gdansk, Gdansk, Poland ${ }^{3}$ Department of Medical Psychology, Medical University of Innsbruck, Innsbruck, Austria

${ }^{4}$ Department of Cardiology and Cardiosurgery, Division of Cardiology and Internal Diseases, University of Warmia and Mazury, Olsztyn, Poland

Submitted: 3 March 2014

Accepted: 14 July 2014

Arch Med Sci 2016; 12, 2: 326-333

DOI: 10.5114 /aoms.2014.47881

Copyright $\odot 2016$ Termedia \& Banach

\section{Abstract}

Introduction: Quality of life measures are useful when interventions or treatments are indicated for several reasons such as improvement of physical functioning, pain relief, to estimate the effectiveness of therapies or to predict mortality. The aim of the current study was to describe quality of life in patients with stable coronary artery disease, myocardial infarction and heart failure and to evaluate the relationship between depression and health-related quality of life.

Material and methods: Patients after STEMI, with stable coronary artery disease, and heart failure $(n=332)$ completed the MacNew Heart Disease Health-related Quality of Life Questionnaire and the Hospital Anxiety and Depression Scale.

Results: Patients with myocardial infarction had significantly higher scores than patients with stable coronary artery disease or heart failure on the MacNew global scale $(p<0.001)$ and the physical $(p<0.001)$, emotional $(p<0.001)$ and social $(p<0.001)$ subscales. The anxiety scores were significantly higher in the group of patients with stable coronary artery disease than in patients with myocardial infarction $(p<0.05)$. The depression scores were significantly higher in patients with heart failure $(p<0.01)$.

Conclusions: In patients with stable CAD, anxiety correlated mainly with symptoms, i.e. angina, than with the history of MI. Patients with symptoms of angina react to the illness with anxiety more than depression, whereas patients with heart failure with dyspnea react to the illness with depressive symptoms more than anxiety. In patients after MI and with stable CAD, cognitive-behavioral techniques could be useful to quickly reduce the level of anxiety, while patients with heart failure require long-term support therapy to reduce the risk of depressive symptoms.

Key words: health-related quality of life, angina, myocardial infarction, heart failure.

\section{Introduction}

Coronary heart disease (CHD) is the main cause of death in Poland [1]. The aims in the treatment of patients with CHD are to relieve symptoms, to maximize function in everyday life, and to achieve the highest level of health-related quality of life (HRQL) within the specific limits imposed by CHD. The World Health Organization defines quality of life

\author{
Corresponding author: \\ Joanna M. Moryś \\ Department of Clinical \\ Psychology \\ Medical University of Gdansk \\ 15 Tuwima St \\ 80-210 Gdansk, Poland \\ Phone: +4858 3491792 \\ E-mail: jmb@gumed.edu.pl
}


as 'an individual's perception of their position in life in the context of the culture and value systems in which they live, and in relation to their goals, expectations, standards and concerns. It is a broad ranging concept affected in a complex way by the person's physical health, psychological state, personal beliefs, social relationships and their relationship to salient features of their environment' [2]. In a clinical setting, assessment of patient-reported outcomes focuses on HRQL, i.e., how physical, emotional and social well-being are affected by a disease or its treatment [1, 3-5]. Patients with CHD experience numerous symptoms including fatigue, dyspnea, stenocardia or edema, and it is important to assess how the disease or its treatment impacts on the patient's physical, emotional and social well-being [1].

The aim of the current study was to describe HRQL in patients with stable coronary artery disease, myocardial infarction (MI) or heart failure. The secondary aim was to evaluate the relationship between anxiety and depression and HRQL.

\section{Material and methods}

\section{Study sample}

Consecutive patients who gave written consent hospitalized in the Department of Cardiology, Medical University of Gdansk, or referred for cardiac rehabilitation in the health clinic Leśnik, Helios in Sopot and Neptun in Wieżyca were recruited for the international HeartQoL Project [6]. The enrollment lasted 8 months in 2007. Patients were eligible if they had an objective measure of coronary artery disease (CAD) (e.g., previous MI, exercise testing, echocardiogram, nuclear imaging, or angiography). Patients were treated for:

A) stable coronary artery disease (Canadian Cardiovascular Society class II, III or IV) without a history of myocardial infarction (MI); or

B) 4 weeks to 6 months after ST elevation MI (STEMI) during rehabilitation course; or

C) diagnosed ischemic heart failure (New York Heart Association Class II, III or IV), with evidence of left ventricular dysfunction (ejection fraction $\leq 40 \%$ by invasive or non-invasive testing).

According to these criteria, we divided the group into 3 subgroups of patients.

Additional eligibility criteria included age 18 years and older, no serious psychiatric disorders, no present substance abuse and able to complete the questionnaires.

The questionnaires were completed by patients with stable CAD a day after elective coronary angiography or elective percutaneous coronary intervention $(\mathrm{PCl})$, whereas in patients after $\mathrm{MI}$ and patients with diagnosed ischemic heart failure they were completed during the rehabilitation course.

\section{Research tools}

To evaluate HRQL in patients with CAD we used the MacNew Heart Disease Health-related Quality of Life Questionnaire (MacNew) [7, 8]. The MacNew questionnaire is a 27-item questionnaire with a global scale and a physical (13-item), an emotional (14-item) and a social (13-item) subscale. The MacNew questionnaire is designed to assess the patient's feelings about how ischemic heart disease (IHD) affects daily functioning, and each item is scored from 1 (low HRQL) to 7 (high $\mathrm{HRQL}$ ) with the minimal important difference (MID) of 0.50 points on the 7-point MacNew global scale and each subscale [9]. A score is generated for each of the Physical, Social and Emotional HeartQoL subscales as the mean of the number of subscale items with a response. The HeartQoL Global (Physical, Social, and Emotional) score is the sum of the score on all scored items divided by the number of scored items. As part of the international HeartQoL Project [6], the MacNew questionnaire was translated into Polish using forward-backward translation.

To determine the presence or absence of anxiety and depression, we used the Hospital Anxiety and Depression Scale (HADS), which is a screening instrument to identify symptoms of anxiety and depression [10]. Seven of the items relate to anxiety and seven relate to depression. Each item on the HADS is scored from 0 to 3 , and this means that a person can score between 0 and 21 for either anxiety or depression. A score of 8 or more is used to classify patients with symptoms of either depression or anxiety [11].

\section{Statistical analysis}

Patient clinical and sociodemographic characteristics are described as either dichotomous (\%) or continuous variables (mean $\pm \mathrm{SD}$ ). MacNew HRQL scale scores (mean \pm SD) were calculated using established scoring criteria for each instrument. Comparisons among cardiac diagnostic groups were made using analysis of variance (ANOVA) (continuous variables) and the $\chi^{2}$ test (categorical variables). The assumptions for ANOVA (normality and homoscedasticity) were tested by Kolmogorov-Smirnov, skewness, and kurtosis statistics. The Spearman correlation coefficient was used to calculate relationships between the continuous variables. Statistical significance was established at $p \leq 0.05$. SPSS version 16.0 (SPSS, Inc., Chicago, Illinois) was used for statistical analyses.

\section{Results}

\section{Patient characteristics}

Baseline sociodemographic and clinical variables were collected on the 332 patients (stable cor- 
Table I. Sociodemographic and clinical characteristics of patients as a total group and the subgroups of patients with stable coronary artery disease (Stable CAD), myocardial infarction (MI) or heart failure (HF)

\begin{tabular}{|c|c|c|c|c|c|}
\hline Patients' characteristics & $\begin{array}{l}\text { Total group } \\
(n=332)\end{array}$ & $\begin{array}{l}\text { Stable CAD } \\
\quad(n=115)\end{array}$ & $\begin{array}{c}\text { MI } \\
(n=112)\end{array}$ & $\begin{array}{c}\mathrm{HF} \\
(n=105)\end{array}$ & Value of $p$ \\
\hline Age, mean \pm SD [years] & $60.2 \pm 10.1$ & $58.4 \pm 8.6$ & $59.1 \pm 10.4$ & $63.4 \pm 10.5$ & $<0.005^{b, c}$ \\
\hline \multicolumn{6}{|l|}{ Gender (\%): } \\
\hline Male & 74.4 & 71.3 & 71.4 & 81.0 & NS \\
\hline Female & 25.6 & 28.7 & 28.6 & 19.0 & \\
\hline \multicolumn{6}{|l|}{ Family status (\%): } \\
\hline Single & 15.4 & 12.2 & 17.0 & 17.1 & NS \\
\hline Married & 75.3 & 82.6 & 70.5 & 72.4 & \\
\hline Other & 9.3 & 5.2 & 12.5 & 10.5 & \\
\hline \multicolumn{6}{|l|}{ Employment (\%): } \\
\hline White collar & 44.6 & 49.6 & 45.5 & 38.1 & NS \\
\hline Blue collar & 55.4 & 50.4 & 54.5 & 61.9 & \\
\hline \multicolumn{6}{|l|}{ Education (\%): } \\
\hline$<$ High school & 40.7 & 33.0 & 39.3 & 50.5 & NS \\
\hline High school & 40.1 & 43.5 & 43.8 & 32.4 & \\
\hline$>$ High school & 19.3 & 23.5 & 17.0 & 17.1 & \\
\hline $\mathrm{BMI}^{\star}$, mean $\pm \mathrm{SD}$ & $28.0 \pm 4.4$ & $29.1 \pm 4.1$ & $27.6 \pm 3.9$ & $27.2 \pm 4.9$ & $<0.01^{a, c}$ \\
\hline Smoker (\%) & 25.9 & 21.7 & 35.7 & 20.0 & NA \\
\hline Hypertensive (\%) & 59.9 & 73.0 & 56.3 & 49.5 & NA \\
\hline Diabetic (\%) & 23.2 & 25.2 & 16.1 & 28.6 & $\begin{array}{l}<0.05^{b} \\
<0.01^{c}\end{array}$ \\
\hline Hypercholesterolemia (\%) & 55.7 & 65.2 & 56.3 & 44.8 & NA \\
\hline Physically inactive* & 54.5 & 68.7 & 46.4 & 47.6 & NA \\
\hline
\end{tabular}

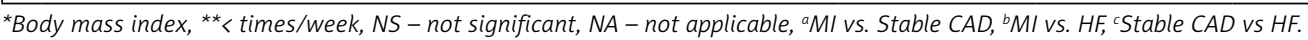

onary artery disease, $n=115 ; \mathrm{MI}, n=112 ; \mathrm{HF}, n=$ 105) recruited for the study, and these are detailed for the total group and each diagnosis in Table I.

Total group $(n=332)$ : With an average age of $60 \pm 10$ years, $74.4 \%$ were males ranging in age from 33 to 84 years (mean $59 \pm 10$ ), and $25.6 \%$ were females ranging in age from 39 to 84 years (mean $63 \pm 11$ ). In the total group $25.9 \%$ reported that they were current smokers and $54.5 \%$ exercised less than three times per week; $59.9 \%$ reported that their physician had told them they were hypertensive, $23.2 \%$ diabetic, and $55.7 \%$ hypercholesterolemic. Two patients had a history of cancer ( $0.6 \%$ of the group), 2 were dialyzed (0.6\%), $17(5.1 \%)$ had a history of gastrointestinal symptoms, 14 (4.2\%) had respiratory symptoms, 18 (5.4\%) had neurological complaints, and 24 patients $(7.2 \%)$ had disorders of the urinary system.

There were no significant differences between the three groups in terms of their comorbidity.
Stable CAD with stable coronary artery disease $(n=115)$ : The average age of patients with stable coronary artery disease was $58.4 \pm 8.6 ; 71.3 \%$ were men aged from 33 years to 78 years (mean $58.7 \pm 10.0$ ), and $28.7 \%$ were women aged from 39 years to 81 years (mean $59.1 \pm 7.8$ ). In this group, $21.7 \%$ reported that they were current smokers, and $68.7 \%$ exercised less than three times per week; $73.0 \%$ reported that their physician had told them they were hypertensive, $25.2 \%$ diabetic, and $65.2 \%$ hypercholesterolemic. Among the patients, $77.4 \%$ were in CCS class II, $18.3 \%$ were in CCS class III, and $4.3 \%$ were in CCS class IV.

Myocardial infarction $(n=112)$ : The average age of patients with $\mathrm{MI}$ was $59.1 \pm 10.4 ; 71.4 \%$ were men aged from 41 years to 84 years $(57.8 \pm 9.7)$, and $28.6 \%$ were women aged from 39 years to 76 years (mean $62.4 \pm 11.6$ ). In this group, $35.7 \%$ reported that they were current smokers, and $46.4 \%$ exercised less than three times per week; $56.3 \%$ reported that their physician had told them they 
were hypertensive, $16.1 \%$ diabetic, and $56.3 \%$ hypercholesterolemic. All patients were treated with percutaneous coronary intervention $(\mathrm{PCl})$.

Heart failure $(n=105)$ : The average age of patients with $\mathrm{HF}$ was $63.4 \pm 10.5$. Among the patients with $\mathrm{HF}, 81 \%$ were men aged from 36 years to 82 years (mean $61.7 \pm 10.0$ ), and $19 \%$ were women aged from 50 years to 84 years (mean $70.5 \pm 9.7$ ). In this group, $20.0 \%$ reported that they were current smokers, and $47.6 \%$ exercised less than three times per week; $49.5 \%$ reported that their physician had told them they were hypertensive, $28.6 \%$ diabetic, and $44.8 \%$ hypercholesterolemic. Among the patients, $77.4 \%$ were in functional NYHA class II, $33.3 \%$ were in functional NYHA class III, and $1 \%$ were in functional NYHA class IV.

\section{Health-related quality of life}

Patients with MI had significantly better HRQL than patients with stable coronary artery disease or heart failure, with higher scores on the MacNew global scale and each subscale. There were no differences between patients with stable coronary artery disease and those with heart failure (Figure 1).

The difference between patients with $\mathrm{MI}$ and patients with either stable coronary artery disease or heart failure exceeded the MID of 0.50 points on the MacNew global scale, the physical and the social subscales and met or exceeded the MID on the emotional subscale.

The level of HADS anxiety was significantly higher in patients with stable coronary artery disease than patients with MI. Anxiety scores did not differ significantly between patients with $\mathrm{Ml}$ and heart failure or between patients with stable coronary artery disease and those with heart failure. The HADS depression scores were significantly higher in patients with heart failure than those with MI. There were no significant depression score differences between patients with stable coronary artery disease and heart failure or between patients with stable coronary artery disease and patients with MI (Table II).

\section{Anxiety and depression}

The presence of anxiety and depression symptoms (HADS score $\geq 8$ ) in the total group was reported by $45.2 \%$ of the total group for anxiety and by $31.3 \%$ for depression (Figure 2). Patients with $\mathrm{MI}$ most frequently reported anxiety symptoms $(57.10 \%)$, whereas symptoms of depression were most frequently reported by patients with heart failure (37.10\%). The differences in the results obtained in different groups of patients for both depression and anxiety are statistically insignificant.

\section{Relationship between HRQL and HADS anxiety and depression}

Correlation analysis between the level of HADS anxiety and depression and MacNew HRQL in the total group and by diagnosis demonstrated a significant negative relationship between HADS anx-

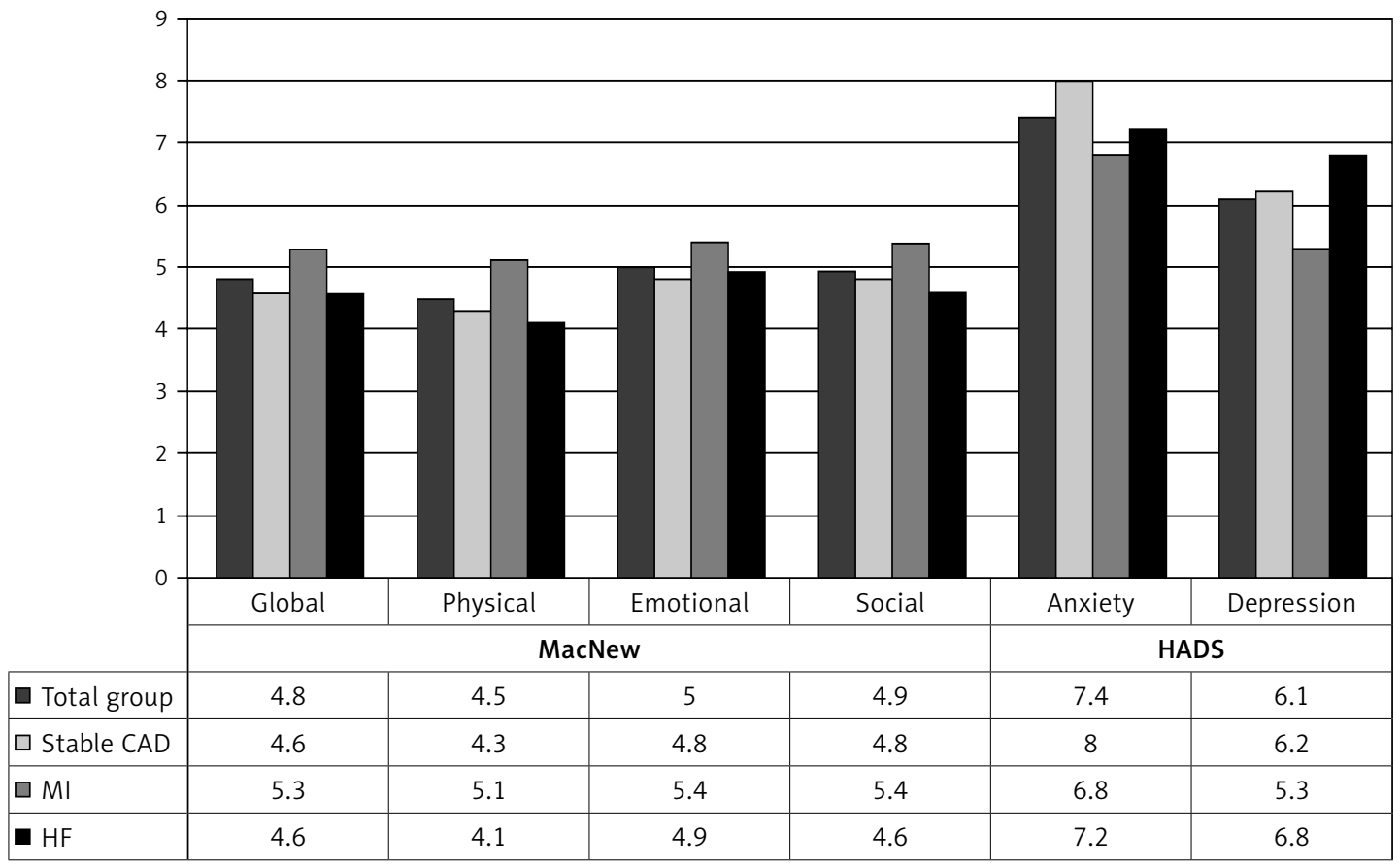

Figure 1. Patients' quality of life (global, as well as physical, emotional and social aspects) and depression level. Mean MacNew and HADS scores in the total group and the subgroups of patients with stable coronary artery disease (stable CAD), myocardial infarction (MI) or heart failure (HF) 
Table II. Mean MacNew and Hospital and Anxiety Scale (HADS) scores ( \pm standard deviation) in the total group and the subgroups of patients with stable coronary artery disease (stable CAD), myocardial infarction (MI) or heart failure (HF)

\begin{tabular}{|c|c|c|c|c|c|}
\hline Scale & Total group & Stable CAD & MI & $\mathrm{HF}$ & Value of $p$ \\
\hline \multicolumn{6}{|l|}{ MacNew: } \\
\hline Global & $4.8 \pm 1.0$ & $4.6 \pm 0.8$ & $5.3 \pm 0.9$ & $4.6 \pm 1.0$ & $<0.001^{a, b}$ \\
\hline Physical & $4.5 \pm 1.2$ & $4.3 \pm 0.9$ & $5.1 \pm 1.1$ & $4.1 \pm 1.2$ & $<0.001^{\mathrm{a}, \mathrm{b}}$ \\
\hline Emotional & $5.0 \pm 1.0$ & $4.8 \pm 0.9$ & $5.4 \pm 1.0$ & $4.9 \pm 1.0$ & $<0.001^{a, b}$ \\
\hline Social & $4.9 \pm 1.1$ & $4.8 \pm 1.0$ & $5.4 \pm 1.1$ & $4.6 \pm 1.1$ & $<0.001^{a, b}$ \\
\hline \multicolumn{6}{|l|}{ HADS: } \\
\hline Anxiety & $7.4 \pm 3.7$ & $8.0 \pm 3.6$ & $6.8 \pm 3.5$ & $7.2 \pm 4.1$ & $<0.05^{a}$ \\
\hline Depression & $6.1 \pm 3.6$ & $6.2 \pm 3.5$ & $5.3 \pm 3.5$ & $6.8 \pm 3.7$ & $<0.01^{b}$ \\
\hline
\end{tabular}

${ }^{a} M I$ vs. stable CAD, ${ }^{b} \mathrm{MI}$ vs. HF, ${ }^{c}$ Stable CAD vs. HF

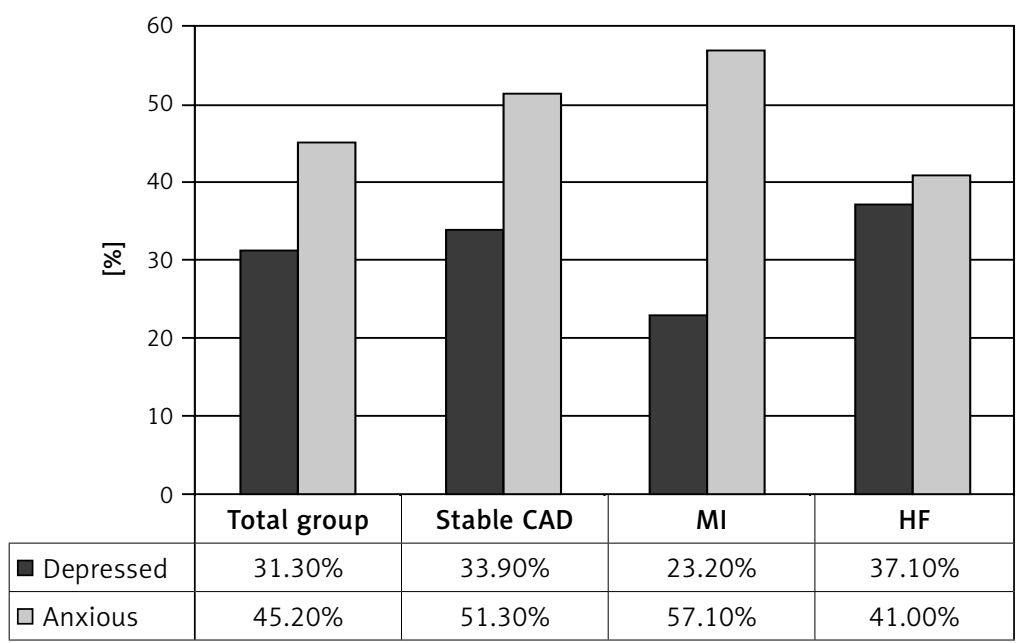

Figure 2. Prevalence of depression and anxiety symptoms in the total group and the subgroups of patients with stable coronary artery disease (Stable CAD), myocardial infarction (MI) or heart failure (HF)

iety and depression and MacNew HRQL, with correlations ranging from -0.37 to -0.57 for anxiety and from -0.46 to -0.58 for depression (Table III).

\section{Discussion}

Quality of life measures are useful when interventions or treatments are indicated for several reasons such as improvement of physical functioning, pain relief, to estimate the effectiveness of therapies and to predict mortality $[1,3,12]$. Studies of HRQL have examined various populations of patients with CHD including survivors of an acute $\mathrm{MI}$, patients who have undergone coronary artery bypass surgery (CABG) or percutaneous coronary intervention $(\mathrm{PCl})$, patients suffering from ischemic heart failure, patients enrolled in cardiac rehabilitation, and patients who have never experienced an acute event or procedure but nonetheless suffer from chronic stable coronary artery disease [13-17].

In our study, we compared quality of life in each of the three diagnostic groups of patients - sta- ble coronary artery disease, heart failure, and $\mathrm{MI}$ - using the MacNew questionnaire [7, 8]. Our findings show significant differences in assessment of HRQL between the group of patients with $\mathrm{MI}$ and patients with either stable coronary artery disease or heart failure, who both have significantly poorer HRQL. These observations applied to the global MacNew HRQL and each of the three dimensions. Physical limitation due to heart failure and discomfort in the chest due to stable coronary artery disease significantly impact the assessment of quality of life, as reported before [18-21].

Patients with symptoms of stable coronary artery disease react to their illness with anxiety more than depression, whereas patients with heart failure with dyspnea react with symptoms of depression more than anxiety.

Several studies have reported that depression and anxiety predict subsequent mortality in patients with $\mathrm{CHD}[22,23]$. Anxiety is common in cardiovascular diseases [22], and a high proportion 
Table III. Correlation between HADS anxiety and depression symptoms and HRQL in the total group and the subgroups of patients with stable coronary artery disease (stable CAD), myocardial infarction (MI) or heart failure (HF)

\begin{tabular}{|c|c|c|c|c|c|}
\hline Scale & Value & Total group & Stable CAD & MI & $\mathrm{HF}$ \\
\hline \multicolumn{6}{|l|}{ Anxiety: } \\
\hline \multirow[t]{2}{*}{ Global } & $r$ & -0.53 & -0.57 & -0.50 & -0.53 \\
\hline & $p$ & $<0.001$ & $<0.001$ & $<0.001$ & $<0.001$ \\
\hline \multirow[t]{2}{*}{ Physical } & $r$ & -0.36 & -0.39 & -0.39 & -0.34 \\
\hline & $p$ & $<0.001$ & $<0.001$ & $<0.001$ & $<0.001$ \\
\hline \multirow[t]{2}{*}{ Emotional } & $r$ & -0.62 & -0.64 & -0.53 & -0.67 \\
\hline & $p$ & $<0.001$ & $<0.001$ & $<0.001$ & $<0.001$ \\
\hline \multirow[t]{2}{*}{ Social } & $r$ & -0.41 & -0.46 & -0.37 & -0.40 \\
\hline & $p$ & $<0.001$ & $<0.001$ & $<0.001$ & $<0.001$ \\
\hline \multicolumn{6}{|l|}{ Depression: } \\
\hline \multirow[t]{2}{*}{ Global } & $r$ & -0.58 & -0.58 & -0.57 & -0.56 \\
\hline & $p$ & $<0.001$ & $<0.001$ & $<0.001$ & $<0.001$ \\
\hline \multirow[t]{2}{*}{ Physical } & $r$ & -0.48 & -0.48 & -0.46 & -0.44 \\
\hline & $p$ & $<0.001$ & $<0.001$ & $<0.001$ & $<0.001$ \\
\hline \multirow[t]{2}{*}{ Emotional } & $r$ & -0.63 & -0.64 & -0.62 & -0.60 \\
\hline & $p$ & $<0.001$ & $<0.001$ & $<0.001$ & $<0.001$ \\
\hline \multirow[t]{2}{*}{ Social } & $r$ & -0.53 & -0.52 & -0.46 & -0.54 \\
\hline & $p$ & $<0.001$ & $<0.001$ & $<0.001$ & $<0.001$ \\
\hline
\end{tabular}

$r$-Pearson's correlation coefficient.

of depressed patients with CHD also have anxiety symptoms due to co-morbid socioeconomic factors [24-26]. In our study, we observed a higher prevalence of anxiety symptoms than depression symptoms in the total group: $45.2 \%$ vs. $31.3 \%$, respectively. In the group of patients with anxiety symptoms, the highest prevalence was observed in patients with $\mathrm{MI}(57.1 \%)$; the proportion of patients with $\mathrm{Ml}$ and anxiety symptoms in our study is considerably higher than in other studies, where symptoms of anxiety were observed in about $19 \%$ soon after $\mathrm{MI}[27,28]$. In our study, $41.0 \%$ of patients with HF reported anxiety symptoms, which is consistent with other studies which examined co-morbid anxiety in HF patients, where the range of anxiety symptoms reported was from $11 \%$ to $45 \%$ [29-31].

Depression is common in patients with CHD [23], and a high proportion of anxious patients with CHD also suffer co-morbid depression disorders [26, 32, 33]. In the group of patients with depressive symptoms, the highest prevalence in our study was observed in patients with HF (37.1\%), which was at the higher end of results reported in other studies, where the prevalence of depression in patients with HF ranged from $15 \%$ to $40 \%$ [3436]. The prevalence rate of depression symptoms was $23.5 \%$ in patients with $\mathrm{Ml}$, which is consistent with other studies, where the range of prevalence rates of major depression within 2 weeks after the MI was $16 \%$ to $27 \%$ [37-43].
There is evidence that both anxiety and depression predict HRQL in patients with CHD [44]. Our study indicates a negative correlation between the symptoms of both the HADS level of anxiety and depression scale and HRQL in the total group and in all three subgroups. This is consistent with other studies, where depression and anxiety after MI predict poorer HRQL, less effective cardiac rehabilitation, and more frequent visits to the cardiac outpatient clinic [45-47]. Other studies reported that the relationship between depression and HRQL may be dependent on the degree of functional impairment $[18,19]$.

In conclusion, in patients with CAD, anxiety correlated mainly with symptoms, i.e. stable coronary artery disease, than with the history of MI. This observation will individualize psychotherapeutic interventions. In patients after myocardial infarction and with stable coronary artery disease, cognitive-behavioral techniques could be useful to quickly reduce the level of anxiety and increase the competence of the patient in the control of anxiety. Patients with heart failure require long-term support therapy to reduce the risk of depressive symptoms. The highest MacNew HRQL scores were reported by patients after myocardial infarction. Patients with heart failure and stable coronary artery disease reported similar MacNew HRQL scores. HADS anxiety symptoms were reported by more than half of patients with either stable coronary artery disease $(51.3 \%)$ or $\mathrm{MI}(57.1 \%)$, where- 
as HADS depression symptoms were reported less frequently, with the highest prevalence rate reported by patients with heart failure (37.1\%).

\section{Acknowledgments}

We would like to thank Neil Oldridge for his editorial assistance and the HeartQoL Steering Committee for giving us access to the Polish HeartQoL data set.

\section{Conflict of interest}

The authors declare no conflict of interest.

\section{References}

1. Spertus JA. Evolving applications for patient-centered health status measures. Circulation 2008; 118: 2103-10.

2. Skevington SM, Lotfy M, O'Connell KA. The World Health Organization's WHOQOL-BREF quality of life assessment: psychometric properties and results of the international field trial. A report from the WHOQOL group. Qual Life Res 2004; 13: 299-310.

3. Rumsfeld JS, Alexander KP, Goff DC Jr, et al. Cardiovascular health: the importance of measuring patient-reported health status: a scientific statement from the American Heart Association. Circulation 2013; 127: 2233-49.

4. Kochańska A, Zarzycka B, Świątecka G, et al. Quality of life in patients with an implantable cardioverter-defibrillator: the significance of clinical factors. Arch Med Sci 2008; 4: 409-16.

5. Chudek J, Kowalczyk A, Kowalczyk AK, et al. Quality of life (QOL) evaluation after acute coronary syndrome with simultaneous clopidogrel treatment. Arch Med Sci 2014; 10: 33-8.

6. Oldridge N, Saner H, McGee HM. The Euro Cardio-QoL Project. An international study to develop a core heart disease health-related quality of life questionnaire, the HeartQoL. Eur J Cardiovasc Prev Rehabil 2005; 12: 87-94.

7. Lim LL, Valenti LA, Knapp JC, et al. A self-administered quality-of-life questionnaire after acute myocardial infarction. J Clin Epidemiol 1993; 46: 1249-56.

8. Valenti L, Lim L, Heller RF, Knapp J. An improved questionnaire for assessing quality of life after acute myocardial infarction. Qual Life Res 1996; 5: 151-61.

9. Dixon T, Lim LL, Oldridge NB. The MacNew heart disease health-related quality of life instrument: reference data for users. Qual Life Res 2002; 11: 173-83.

10. Zigmond AS, Snaith RP. The hospital anxiety and depression scale. Acta Psychiatr Scand 1983; 67: 361-70.

11. Bjelland I, Dahl AA, Haug TT, Neckelmann D. The validity of the Hospital Anxiety and Depression Scale. An updated literature review. J Psychosom Res 2002; 52: 69-77.

12. Feola M, Lombardo E, Testa M, et al. Prognostic factors of mid-term clinical outcome in congestive heart failure patients discharged after acute decompensation. Arch Med Sci 2012; 8: 462-70.

13. Mommersteeg PM, Denollet J, Spertus JA, Pedersen SS. Health status as a risk factor in cardiovascular disease: a systematic review of current evidence. Am Heart J 2009; 157: 208-18.

14. Oldridge N. Exercise-based cardiac rehabilitation in patients with coronary heart disease: meta-analysis outcomes revisited. Future Cardiol 2012; 8: 729-51.

15. Shepherd CW, While AE. Cardiac rehabilitation and quality of life: a systematic review. Int J Nurs Stud 2012; 49: 755-71.
16. Folga A, Filipiak KJ, Mamcarz A, et al. Simultaneous predictive value of NT-proBNP and CA-125 in patients newly diagnosed with advanced heart failure: preliminary results. Arch Med Sci 2012; 8: 637-43.

17. Uematsu M, Akashi YJ, Ashikaga K, et al. Association between heart rate at rest and myocardial perfusion in patients with acute myocardial infarction undergoing cardiac rehabilitation - a pilot study. Arch Med Sci 2012; 8: 622-30.

18. Faller H, Steinbuchel T, Stork S, et al. Impact of depression on quality of life assessment in heart failure. Int J Cardiol 2010; 142: 133-7.

19. Ruo B, Rumsfeld JS, Hlatky MA, et al. Depressive symptoms and health-related quality of life: the Heart and Soul Study. JAMA 2003; 290: 215-21.

20. Atienza F, Velasco JA, Brown S, et al. Assessment of quality of life in patients with chest pain and normal coronary arteriogram (syndrome $X$ ) using a specific questionnaire. Clin Cardiol 1999; 22: 283-90.

21. Kiessling A, Henriksson P. Time trends of chest pain symptoms and health related quality of life in coronary artery disease. Health Qual Life Outcomes 2007; 5: 13.

22. Roest AM, Martens EJ, de JP, Denollet J. Anxiety and risk of incident coronary heart disease: a meta-analysis. J Am Coll Cardiol 2010; 56: 38-46.

23. Blumenthal JA. Depression and coronary heart disease: association and implications for treatment. Cleve Clin J Med 2008; 75 Suppl. 2: S48-53.

24. Bankier B, Januzzi JL, Littman AB. The high prevalence of multiple psychiatric disorders in stable outpatients with coronary heart disease. Psychosom Med 2004; 66: 645-50.

25. Denollet J, Strik JJ, Lousberg R, Honig A. Recognizing increased risk of depressive comorbidity after myocardial infarction: looking for 4 symptoms of anxiety-depression. Psychother Psychosom 2006; 75: 346-52.

26. Watkins LL, Koch GG, Sherwood A, et al. Association of anxiety and depression with all-cause mortality in individuals with coronary heart disease. J Am Heart Assoc 2013; 2: 1-10.

27. Hanssen TA, Nordrehaug JE, Eide GE, et al. Anxiety and depression after acute myocardial infarction: an 18-month follow-up study with repeated measures and comparison with a reference population. Eur J Cardiovasc Prev Rehabil 2009; 16: 651-9.

28. Khan MA, Karamat M, Hafizullah M, et al. Frequency of anxiety and psychosocial stressful events in patients with acute myocardial infraction. J Ayub Med Coll Abbottabad 2010; 22: 32-5.

29. Yu DS, Thompson DR, Yu CM, Oldridge NB. Assessing HRQL among Chinese patients with coronary heart disease: angina, myocardial infarction and heart failure. Int J Cardiol 2009; 131: 384-94.

30. Schweitzer RD, Head K, Dwyer JW. Psychological factors and treatment adherence behavior in patients with chronic heart failure. J Cardiovasc Nurs 2007; 22: 76-83.

31. Friedmann E, Thomas SA, Liu F, et al. Relationship of depression, anxiety, and social isolation to chronic heart failure outpatient mortality. Am Heart J 2006; 152: 940-8.

32. Clarke DM, Currie KC. Depression, anxiety and their relationship with chronic diseases: a review of the epidemiology, risk and treatment evidence. Med J Aust 2009; 190: S54-60.

33. Compare A, Germani E, Proietti R, Janeway D. Clinical psychology and cardiovascular disease: an up-to-date clinical practice review for assessment and treatment 
of anxiety and depression. Clin Pract Epidemiol Ment Health 2011; 7: 148-56.

34. Kop WJ, Synowski SJ, Gottlieb SS. Depression in heart failure: biobehavioral mechanisms. Heart Fail Clin 2011; 7: 23-38.

35. Rutledge T, Reis VA, Linke SE, et al. Depression in heart failure a meta-analytic review of prevalence, intervention effects, and associations with clinical outcomes. J Am Coll Cardiol 2006; 48: 1527-37.

36. Rumsfeld JS, Havranek E, Masoudi FA, et al. Depressive symptoms are the strongest predictors of short-term declines in health status in patients with heart failure. J Am Coll Cardiol 2003; 42: 1811-7.

37. Larsen KK, Vestergaard M, Sondergaard J, Christensen B. Screening for depression in patients with myocardial infarction by general practitioners. Eur J Prev Cardiol 2013; 20: 800-6.

38. Thombs BD, Bass EB, Ford DE, et al. Prevalence of depression in survivors of acute myocardial infarction. J Gen Intern Med 2006; 21: 30-8.

39. Ketterer MW, Bekkouche NS, Goldberg AD, et al. Symptoms of anxiety and depression are correlates of angina pectoris by recent history and an ischemia-positive treadmill test in patients with documented coronary artery disease in the pimi study. Cardiovasc Psychiatry Neurol 2011; 2011: 1-7.

40. Vural M, Satiroglu O, Akbas B, et al. Coronary artery disease in association with depression or anxiety among patients undergoing angiography to investigate chest pain. Tex Heart Inst J 2009; 36: 17-23.

41. Celano CM, Huffman JC. Depression and cardiac disease: a review. Cardiol Rev 2011; 19: 130-42.

42. Tully PJ, Baker RA. Depression, anxiety, and cardiac morbidity outcomes after coronary artery bypass surgery: a contemporary and practical review. J Geriatr Cardiol 2012; 9: 197-208.

43. Huffman JC, Celano CM, Beach SR, et al. Depression and cardiac disease: epidemiology, mechanisms, and diagnosis. Cardiovasc Psychiatry Neurol 2013; 2013 : 695925.

44. Pragodpol P, Ryan C. Critical review of factors predicting health-related quality of life in newly diagnosed coronary artery disease patients. J Cardiovasc Nurs 2013; 28: 277-84.

45. Lane D, Carroll D, Ring C, et al. Effects of depression and anxiety on mortality and quality-of-life 4 months after myocardial infarction. J Psychosom Res 2000; 49: 229-38.

46. Malkoff SB, Muldoon MF, Zeigler ZR, Manuck SB. Blood platelet responsivity to acute mental stress. Psychosom Med 1993; 55: 477-82.

47. Strik JJ, Denollet J, Lousberg R, Honig A. Comparing symptoms of depression and anxiety as predictors of cardiac events and increased health care consumption after myocardial infarction. J Am Coll Cardiol 2003; 42: 1801-7. 